\title{
Validation of a model for optimal birth weight: a prospective study using serial ultrasounds
}

\author{
Gavin Pereira ${ }^{1,2^{*}}$, Eve Blair ${ }^{1}$ and David Lawrence ${ }^{1}$
}

\begin{abstract}
Background: The aim of this study was to validate a model for optimal birth weight derived from neonatal records, and to test the assumption that preterm births may be considered optimally grown if they are not exposed to common factors that perturb fetal growth.
\end{abstract}

Methods: Weights of fetuses were estimated from serial biometric ultrasound scans $(N=2,848)$ and combined with neonatal weights for a prospective pregnancy cohort $(N=691)$. Non-Caucasians, fetuses subsequently born preterm and those with diagnosed or suspected determinants of aberrant growth were excluded leaving fetuses assumed to have experienced normal growth. A generalised linear longitudinal growth model for optimal weight was derived, including terms for gestational duration, infant sex, maternal height and birth order. This model was compared to a published model derived solely from birth weights.

Results: Prior to 30 weeks gestation, the published model yielded systematically lower weights than the model derived from both fetal weight and neonatal weight. From 30 weeks gestation the two models were indistinguishable.

Conclusion: The model for optimal birth weight was valid for births that have attained at least 30 weeks gestation. The model derived from both fetal and neonatal weights is recommended prior to this gestation.

Keywords: Fetal growth, Preterm delivery, Proportion of optimal birth weight

\section{Background}

Standards for fetal weight are typically derived from birth weights of neonates born at different gestational ages $[1,2]$. However, births at early gestations are frequently affected by pathologies that restrict growth [3-5]. Therefore standards of growth derived from birth weights will tend to under-estimate the weight of unborn fetuses of the same gestation, thereby underestimating the degree of growth restriction in infants born preterm [6]. Such situations may lead to inappropriate counselling and planning for preterm delivery [6]. This dilemma is insurmountable by studies considering only birth weight since if preterm births were

\footnotetext{
* Correspondence: gpereira@ichr.uwa.edu.au

${ }^{1}$ Telethon Institute for Child Health Research, Centre for Child Health Research, University of Western Australia, 100 Roberts Road, Subiaco, WA 6008, Australia

${ }^{2}$ Yale School of Public Health, Center for Perinatal, Pediatric and Environmental Epidemiology, Yale University, New Haven, CT 06510, USA
}

excluded no estimate of growth would be available at early gestational ages.

Optimal weight may be interpreted as a result of growth achieved in the absence of any factors that pathologically affect growth. We have previously reported a method of assessing the appropriateness of fetal growth using the proportion of optimal birth weight [7]. With that approach the measure of growth was the ratio of the observed birth weight to the estimated optimal birth weight given the neonate's non-pathologic determinants of growth. In that study 'optimal' weight was defined as the weight achieved by neonatal survivors not exposed to any of the exposures associated with intrauterine growth anomaly commonly occurring in our population; namely: maternal smoking, vascular disease, diabetes (pre-existing or gestational), TORCH infections (toxoplasmosis, rubella, CMV, herpes) in pregnancy, multiple pregnancy and birth defects in the fetus. Gestation of delivery was not a criterion for optimal growth. As anticipated, a far greater proportion of preterm births were excluded by 
these criteria than were term births, but we had no compelling reason for excluding other preterm births on the grounds of growth anomaly, despite their preterm birth suggesting experience of suboptimal exposures. However the assumption that neonatally surviving preterm births not exposed to common causes of growth anomaly are optimally grown was untested.

The aim of this study was to validate a model for optimal birth weight derived from neonatal records, and to query the assumption that preterm births may be considered optimally grown if they are not exposed to common factors that perturb fetal growth.

\section{Method}

Our analytic approach is summarised by the following steps:

i. We selected a sample of optimally grown term births from a randomised controlled trial of serial biometric ultrasound scans in pregnancy. Weight was estimated from biometric measurements made during each ultrasound scan during pregnancy and obtained at the time of birth. ii. A model for optimal weight was derived at each of these measurement occasions using the fetal and neonatal weights as the response variable and nonpathologic determinants of growth as explanatory variables. $\mathrm{OW}_{\mathrm{US}}$ refers to optimal weights derived with this model.

iii. Optimal weight was then derived at each of these measurement occasions using the published model derived using only birth weights from an independent population, $\mathrm{OW}_{\mathrm{BW}}$.

iv. The difference in optimal weight estimated by the two models was calculated at each week of gestation.

\section{Sample selection}

A total of 9,222 serial ultrasound scans were obtained between 1989 and 1991 in Perth Western Australia for 2,860 pregnancies that resulted in a live birth (Figure 1). The cohort were recruited through the Raine Study, which was a randomised trial initially designed to study fetal outcome in relation to the influence of multiple ultrasound scans (scheduled for weeks 18, 24, 28, 34 and

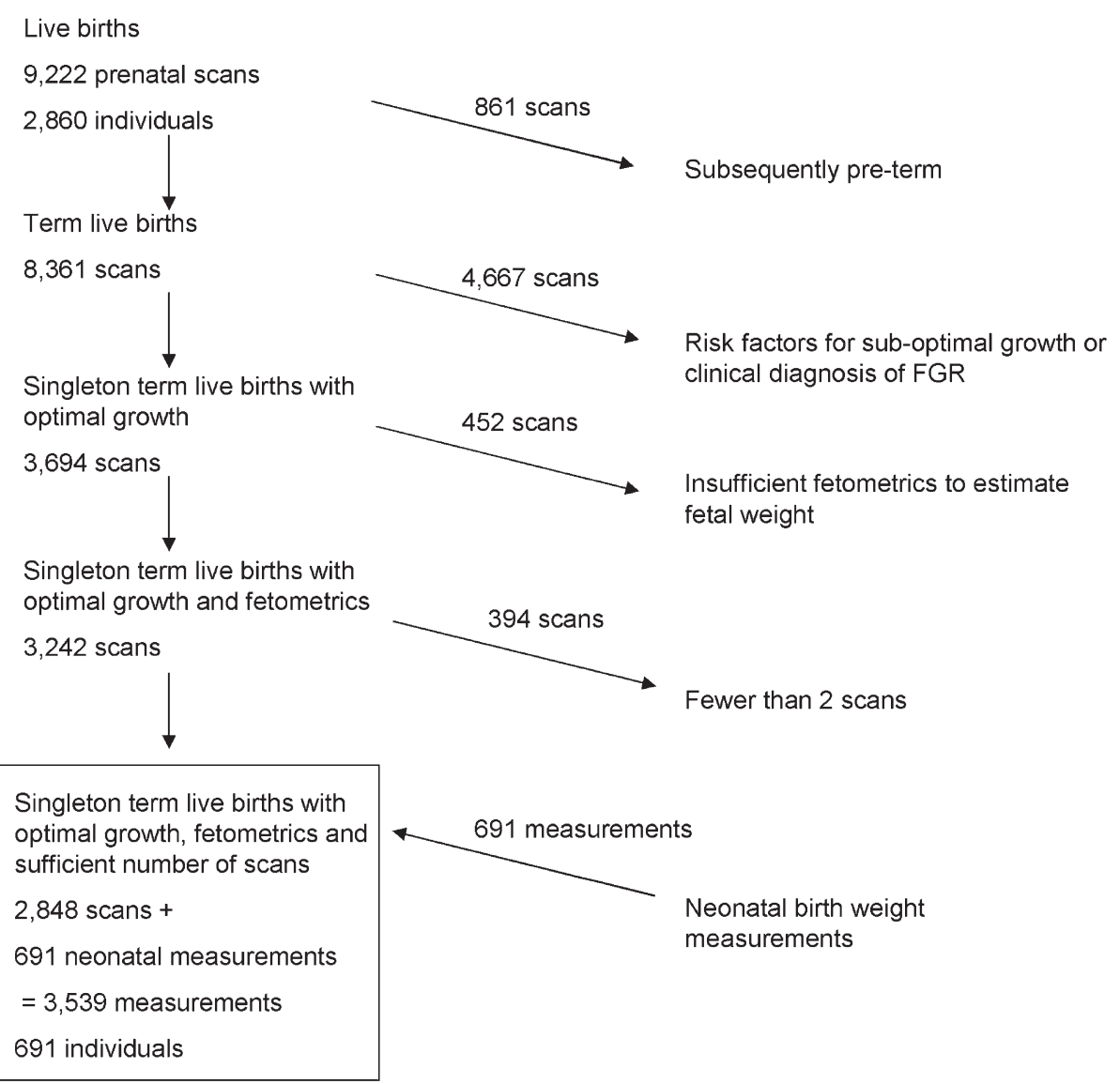

Figure 1 Flow diagram showing exclusions and final sample. 
38 weeks gestation). We excluded scans of fetuses subsequently born preterm.

We then restricted the population to Caucasians and excluded scans of pregnancies complicated by maternal factors associated with growth anomaly (Table 1): maternal smoking, maternal vascular disease (essential hypertension only, gestational hypertension only, gestational hypertension with proteinuria (preeclampsia), essential hypertension with proteinuria), pre-existing or gestational diabetes, multiple pregnancy. Next, scans for a fetus subsequently diagnosed with fetal growth restriction (FGR) under clinical assessment were excluded. Clinical assessment for FGR involves physical examination of the neonate postpartum.

In order to allow for curvature in the growth curves we restricted analysis to individuals who had at least 2 scans i.e. at least 3 weight measurements after including the neonatal record of birth weight. Remaining for analyses were 2,848 serial ultrasound scans for 691 individuals. Neonatal records of birth weights and associated gestational ages $(\mathrm{N}=691)$ were appended to the ultrasounds $(\mathrm{N}=2,848)$, resulting in 3,539 measurements (Table 2).

\section{Calculation of fetal weight from ultrasound scans}

Abdominal circumference (AC), femur length (FL), head circumference (HC) and biparietal diameter (BPD) measurements were obtained from the ultrasounds. Hadlock's formula was applied to estimate fetal weight using $\mathrm{AC}, \mathrm{FL}, \mathrm{HC}$ and BPD measurements taken at or after 27 weeks gestation [8]. In a comparison of 12 equations for fetal weight, Hadlock's 4-variable formula performed well in terms of error bias and error precision for subsequent births over $1000 \mathrm{~g}$ [9]. Scott's formula was applied to estimate fetal weight using $\mathrm{AC}, \mathrm{FL}$ and $\mathrm{HC}$

Table 1 Number of scans and individuals by risk factor for suboptimal growth and clinical diagnoses of FGR among singleton liveborn term neonates

\begin{tabular}{|c|c|c|c|c|}
\hline & \multicolumn{2}{|l|}{ Scans } & \multicolumn{2}{|c|}{ Individuals } \\
\hline & $\mathbf{N}$ & $\%$ & $\mathbf{N}$ & $\%$ \\
\hline Singleton liveborn neonates & 8,361 & 100 & 2496 & 100 \\
\hline Non-Caucasian & 810 & 10 & 242 & 10 \\
\hline Maternal smoking & 2,158 & 26 & 658 & 26 \\
\hline Maternal vascular disease* & 2,140 & 26 & 602 & 24 \\
\hline Congenital anomaly & 24 & 0 & 18 & 1 \\
\hline $\begin{array}{l}\text { Maternal pre-existing or } \\
\text { gestational diabetes }\end{array}$ & 338 & 4 & 80 & 3 \\
\hline Clinically assessed FGR & 224 & 3 & 66 & 3 \\
\hline Any of the above risk factors & 4,667 & 56 & 1365 & 55 \\
\hline
\end{tabular}

*Essential hypertension only, gestational hypertension only, gestational hypertension and proteinuria (preeclampsia), essential hypertension and proteinuria. measurements taken prior to 27 weeks gestation (189 days) as it proved the most accurate in a comparison with 10 other equations at early gestations [10].

\section{Estimation of optimal weight derived from both} ultrasound and neonatal measurements

A predictive model for the expected fetal weight ( $\left.\mathrm{OW}_{\mathrm{US}}\right)$ derived from both the fetal ultrasound scans and neonatal measurements was determined using gestational age, maternal height, birth order and infant sex as predictors. All first order interactions between the predictor variables were considered along with polynomial forms of gestational age. Box-Cox transformations were applied to improve the fit of the model [11]. Despite transformations, the error variance of the growth data increased with the mean. Therefore, a generalized linear model was applied using a gamma distributed response variable and a log link function, which subsequently eliminated heteroskedasticity. As there were repeated ultrasound measures for each fetus, the covariance among the errors for the same individual were assumed to have a power covariance function of the form:

$$
\operatorname{Cov}\left(\epsilon_{t, j}, \epsilon_{t *, j}\right)=\sigma_{\epsilon}^{2} \rho^{d_{t, t *}}
$$

where $\rho$ is the correlation between fetal weight measurements taken a day apart and $d_{t}, t^{*}$ is the interval of time between time $\mathrm{t}$ and time $\mathrm{t}^{*}$. Therefore, measurements taken closer in time were assumed to be more similar than those further apart. The analysis was conducted using the GLIMMIX procedure of SAS version 9.1 [12].

\section{Estimation of optimal weight derived from neonatal measurements only}

The optimal weight $\left(\mathrm{OW}_{\mathrm{BW}}\right)$ was calculated for each record using a previously published model that relied on birth weight measurements [7]:

Table 2 Gestational age distribution for (i) the final study cohort, and (ii) the previous study cohort used to derive a model for optimal weight using only neonatal measurements

\begin{tabular}{llllll}
\hline \multirow{2}{*}{ Gestation } & \multicolumn{2}{c}{ Study cohort } & & \multicolumn{2}{c}{ Previous study cohort } \\
\cline { 2 - 3 } \cline { 5 - 6 } & $\mathbf{N}^{*}$ & $\%$ & & $\mathbf{N}^{* *}$ & $\%$ \\
\hline 14-17 weeks & 147 & 4 & & 0 \\
18-22 weeks & 578 & 16 & & 0 & 0 \\
23-27 weeks & 561 & 16 & & 76 & 0 \\
28-32 weeks & 550 & 16 & & 258 & 0 \\
33-39 weeks & 1,251 & 35 & & 35,575 & 57 \\
40-42 weeks & 452 & 13 & & 26,837 & 43 \\
Total & 3,539 & & 62,746 & \\
\hline
\end{tabular}

* Scans and neonatal measurements.

** Neonatal measurements. 


$$
\mathrm{OW}_{\mathrm{BW}}=\left[\begin{array}{l}
-14.08-1414\left(\frac{\mathrm{GA}}{100}\right)^{3}-2782\left(\frac{\mathrm{GA}}{100}\right)^{3} \ln \left(\frac{\mathrm{GA}}{100}\right)+1.185 \text { Male }+0.1077(\text { Height }-162) \\
+1.028 \text { Second }+1.318 \text { Third }+1.571 \text { More }+0.00667(\mathrm{GA}-40)(\text { Height }-162)
\end{array}\right]^{2}
$$

where GA refers to the gestational age at which the measurement was taken, Male is an indicator variable for male sex, Second refers to the second birth (para 1), Third refers to the third birth (para 2), and More refers to the fourth birth or more. Height is maternal height measured during pregnancy.

In that study, similar exclusion criteria were applied: multiple birth (3\%), maternal smoking during pregnancy (27\%), maternal vascular disease (7\%), congenital anomaly $(6 \%)$ and maternal pre-existing or gestational diabetes (4\%) [7]. The prevalence of maternal vascular disease was higher in this study due to the inclusion of essential hypertension (Table 1).
Model for expected fetal weight from ultrasound scans

The Box-Cox procedure suggested the square root as the optimal transformation. The Pearson correlation between the observed and predicted fetal weights was 0.97 . The square of this correlation, a pseudo R-squared, indicated that the model explained $95 \%$ of the variation in fetal weights. The autocorrelation in the residuals between consecutive days was low but statistically significant, and therefore systematic and non-ignorable $(\rho=0.007191$, $\mathrm{SD}=0.001657)$.

Parameter estimates are shown in Table 4 and the model for $\mathrm{OW}_{\mathrm{US}}$ (grams) expressed as:

$$
\mathrm{EFW}_{\mathrm{US}}=\exp 2\left[\begin{array}{l}
\beta_{0}+\beta_{1}\left(\frac{\text { Time }}{300}\right)+\beta_{2}\left(\frac{\text { Time }}{300}\right)^{2}+\beta_{3}\left(\frac{\text { Time }}{300}\right)^{3}+\beta_{4}\left(\frac{\text { Time }}{300}\right)^{4} \\
+\beta_{5} \text { Male }+\beta_{6} \text { Second }+\beta_{7} \text { Third }+\beta_{8} \text { More }+\beta_{9}(\text { Height }-162) \\
+\beta_{10} \text { Time }(\text { Height }-162)
\end{array}\right]
$$

\section{Comparison between the $\mathrm{OW}_{\mathrm{Us}}$ and $\mathrm{OW}_{\mathrm{BW}}$}

The proportional deviation of $\mathrm{OW}_{\mathrm{BW}}$ from $\mathrm{OW}_{\mathrm{US}}$ was calculated at each gestational age as:

$$
\text { Proportional Deviation }=\frac{\mathrm{OW}_{\mathrm{BW}}-\mathrm{OW}_{\mathrm{US}}}{\mathrm{OW}_{\mathrm{US}}}
$$

The formula for $\mathrm{OW}_{\mathrm{BW}}$ was considered an appropriate representation of $\mathrm{OW}_{\mathrm{US}}$ at gestational ages where the 95\% bootstrap confidence interval [13] for the proportional deviation intersected zero.

\section{Approvals}

Ethics approval was obtained by the Department of Health Western Australia, Human Research Ethics Committee.

\section{Results}

Sample population and ultrasound scan characteristics

There was an approximately equal ratio of male to female births (51:49) (Table 3). Mothers were most likely to be in the 20-29 year (30\%) and 30-34 year (29\%) age groups. Approximately $72 \%$ of the women had at least 4 scans. The 14-17 week and 40-42 week gestational periods were represented by only $147(5 \%)$ and $21(1 \%)$ scans respectively. where Time is the time of gestation represented in days since the last menstrual period.

\section{Comparison between the $\mathrm{OW}_{\mathrm{US}}$ and $\mathrm{OW}_{\mathrm{BW}}$}

The curves for mean $\mathrm{OW}_{\mathrm{BW}}, \mathrm{OW}_{\mathrm{US}}$, and proportional deviation of $\mathrm{OW}_{\mathrm{BW}}$ from $\mathrm{OW}_{\mathrm{US}}$ were calculated from 16 to 39 weeks gestation because few ultrasound scans were conducted outside this interval (Table 3). The curves for mean $\mathrm{OW}_{\mathrm{BW}}$ and $\mathrm{OW}_{\mathrm{US}}$ differed before 2830 weeks when $\mathrm{OW}_{\mathrm{BW}}$ approached zero (Figure 2). The $\mathrm{OW}_{\mathrm{BW}}$ was systematically lower than $\mathrm{OW}_{\mathrm{US}}$ before 30 weeks gestation and the difference was statistically significant prior to 28 completed weeks of gestation (Figure 3). The difference between $\mathrm{OW}_{\mathrm{BW}}$ and $\mathrm{OW}_{\mathrm{US}}$ increased by as much as $10 \%$ per earlier week of gestation.

\section{Sensitivity of the results to the choice of model used to estimate fetal weight}

Hadlock's formula was applied to estimate fetal weight from ultrasound scans at or after 27 weeks gestation [8] and Scott's formula was applied at earlier gestations [10]. We repeated the study using Hadlock's formula instead of Scott's formula to estimate fetal weight from scans taken before 27 weeks gestation. The mean difference 
Table 3 Study characteristics

\begin{tabular}{|c|c|c|}
\hline Characteristic & $\mathrm{N}$ & $\%$ \\
\hline All births & 691 & 100 \\
\hline All scans & 2,848 & 100 \\
\hline \multicolumn{3}{|l|}{ Infant sex } \\
\hline Male & 354 & 51 \\
\hline Female & 337 & 49 \\
\hline \multicolumn{3}{|l|}{ Maternal age (years) } \\
\hline Less than 20 & 58 & 8 \\
\hline $20-24$ & 132 & 19 \\
\hline $25-29$ & 210 & 30 \\
\hline $30-34$ & 201 & 29 \\
\hline 35 or over & 90 & 13 \\
\hline \multicolumn{3}{|l|}{ Birth order } \\
\hline First birth & 308 & 45 \\
\hline Second birth & 215 & 31 \\
\hline Third birth & 108 & 16 \\
\hline Fourth birth or more & 60 & 9 \\
\hline \multicolumn{3}{|c|}{ Scans per gestation period } \\
\hline 14-17 weeks & 147 & 5 \\
\hline 18-22 weeks & 578 & 20 \\
\hline 23-27 weeks & 561 & 20 \\
\hline 28-32 weeks & 550 & 19 \\
\hline 33-39 weeks & 991 & 34 \\
\hline 40-42 weeks & 21 & 1 \\
\hline \multicolumn{3}{|l|}{ Scans per individual } \\
\hline $2-3$ scans & 190 & 28 \\
\hline $4-5$ scans & 459 & 66 \\
\hline $6-8$ scans & 42 & 6 \\
\hline
\end{tabular}

between estimated fetal weight based on Scott's model and Hadlock's model (Scott - Hadlock) was non-zero $(p<0.0001)$ at $10 \mathrm{~g}(\mathrm{SD}=26 \mathrm{~g})$ using fetometric ultrasound measurements taken before 27 weeks gestation. The mean difference between estimated fetal weight based on Scott's model and the previously published model $\left(S c o t t-\mathrm{OW}_{\mathrm{BW}}\right)$ was also non-zero $(p<0.0001)$ at $197 \mathrm{~g}(\mathrm{SD}=68 \mathrm{~g})$ using fetometric ultrasound measurements taken before 27 weeks gestation.

\section{Discussion}

Our study made use of a large prospectively collected sample of serial ultrasounds to derive an estimate of the optimal fetal weight and thereby also a method to ascertain the adequacy of fetal growth. We adopted a multifaceted approach: weight was derived from ultrasound scans taken at multiple occasions during pregnancy and supplemented with weight measured at the time of birth, rather than sole reliance on birth weights and we excluded fetuses subsequently (i) born preterm, (ii) that died before 28 days of life, or (iii) that experienced pathologies affecting growth. We found that estimates of optimal weight based on a population of birth weights also subject to exclusions (ii) and (iii) but not (i) were systematically lower than fetal weight estimated using biometric ultrasounds prior to 30 weeks gestation.

It is plausible that the difference between $\mathrm{OW}_{\mathrm{US}}$ and $\mathrm{OW}_{\mathrm{BW}}$ (Figure 2, Figure 3) suggests an increasing proportion of unusual causes of growth restriction with decreasing gestation of delivery before 28 to 30 weeks gestation, but very few such causes of growth restriction for births after 30 weeks. We re-examined those in the original cohort used to derive $\mathrm{OW}_{\mathrm{BW}}$ that were born at or before 28 weeks gestation $(\mathrm{N}=101)$. Among this group, the recorded antepartum factors that might have contributed to growth restriction but were not excluded as common causes of growth restriction were: threatened abortion (antepartum haemorrhage before 30 weeks gestation), $\mathrm{N}=13$; urinary tract infection, $\mathrm{N}=2$; antepartum haemorrhage (not attributed to placenta previa or abruption), $\mathrm{N}=39$; asthma, $\mathrm{N}=12$; genital tract infection, $\mathrm{N}=9$; vaginitis, $\mathrm{N}=4$; significant psychological morbidity, $\mathrm{N}=11$; anaemia, $\mathrm{N}=5$; neoplasms, $\mathrm{N}=7$. Approximately $63 \%$ of this cohort experienced at least one of these factors. Among all term neonates in Western Australia, the prevalence of asthma was $9.7 \%$ and neoplasms (cervical cancer and cervical dysplasia) was $0.02 \%$, which were both lower than the prevalence in this cohort. Further studies are required to confirm whether maternal asthma, cervical cancers and depression are disproportionately stronger risk factors for growth restriction at such early gestations in other populations. It remains to be demonstrated that preterm births, particularly very preterm births, can be considered optimally grown if they are not exposed to common factors that perturb fetal growth.

Although it is plausible that there is an increasing proportion of unusual causes of growth restriction with decreasing gestation of delivery before 28 to 30 weeks gestation, there are other explanations for the findings. Radiographers may have systematically over or underestimated fetal biometric measurements. However, the measurements were taken by a limited number of experienced radiographers at a tertiary obstetric hospital. While both Hadlock's and Scott's models were selected because they performed favourably compared to alternative formulae, it is possible that both of these methods used to estimate fetal weight from ultrasound measurements systematically over-estimated true fetal weight in our study. Few ultrasound scans were taken within a week of birth among early low-risk preterm births before 28 weeks gestation. This meant that a formal validation of the model used to estimate fetal weight from 
Table 4 Parameter estimates for the square root of optimal fetal weight (grams)

\begin{tabular}{|c|c|c|c|c|c|c|}
\hline \multirow[b]{2}{*}{ Parameter } & \multirow[b]{2}{*}{ Variable } & \multirow[b]{2}{*}{ Estimate } & \multirow[b]{2}{*}{ SE } & \multicolumn{3}{|c|}{$95 \% \mathrm{Cl}$} \\
\hline & & & & Lower & Upper & $p$-value \\
\hline$\overline{\beta_{0}}$ & Intercept & -4.311 & 0.2097 & -4.7223 & -3.8997 & $<.0001$ \\
\hline$\beta_{1}$ & $\frac{\text { Time }}{300}$ & 35.4907 & 1.3364 & 32.8702 & 38.1111 & $<.0001$ \\
\hline$\beta_{2}$ & $\left(\frac{\text { Time }}{300}\right)^{2}$ & -66.8095 & 3.0939 & -72.8763 & -60.7428 & $<.0001$ \\
\hline$\beta_{3}$ & $\left(\frac{\text { Time }}{300}\right)^{3}$ & 61.7716 & 3.0934 & 55.7058 & 67.8373 & $<.0001$ \\
\hline$\beta_{4}$ & $\left(\frac{\text { Time }}{300}\right)^{4}$ & -22.0933 & 1.1304 & -24.3099 & -19.8767 & $<.0001$ \\
\hline$\beta_{5}$ & Male & 0.0112 & 0.003276 & 0.004766 & 0.01763 & 0.0007 \\
\hline$\beta_{6}$ & Second birth & 0.001354 & 0.003832 & -0.00617 & 0.008876 & 0.7239 \\
\hline$\beta_{7}$ & Third birth & 0.01575 & 0.004821 & 0.006291 & 0.02522 & 0.0011 \\
\hline$\beta_{8}$ & Fourth birth or more & 0.02281 & 0.006053 & 0.01093 & 0.03469 & 0.0002 \\
\hline$\beta_{9}$ & Maternal height -162 & -0.00155 & 0.000729 & -0.00298 & -0.00012 & 0.0336 \\
\hline$\beta_{10}$ & Time (Maternal height - 162) & 0.003979 & 0.001003 & 0.002012 & 0.005945 & $<.0001$ \\
\hline
\end{tabular}

ultrasound measurements could not be conducted. However, we confirmed that results were not sensitive to the choice of Hadlock's versus Scott's method to estimate fetal weight from ultrasound measurements. Before 27 weeks gestation, Scott's method and Hadlock's method to estimate fetal weight from ultrasound measurements differed by only $10 \mathrm{~g}$, whereas the difference between estimates obtained from Scott's method and the model for optimal weight derived from birth weight measurements was almost $200 \mathrm{~g}$.

A further alternative explanation for the findings of this study is that the model developed using a combination of fetal weights derived from ultrasound scans and birth weights fits the data better at earlier gestations than the published model derived from birth weights due to the small number of births at early gestations. The model for $\mathrm{OW}_{\mathrm{BW}}$ was developed predominantly on a sample of births from 33 weeks gestation whereas the model for $\mathrm{OW}_{U S}$ was based on measurements from ultrasounds that start typically from much earlier gestations (Table 2). Therefore, the model for $\mathrm{OW}_{\mathrm{US}}$ is recommended for the estimation of fetal weight instead of $\mathrm{OW}_{\mathrm{BW}}$, particularly before 30 weeks gestation.

Our results support the overall findings of Salomon et al (2007) who reported that the median of the fetal weight distribution provided an upper bound for the

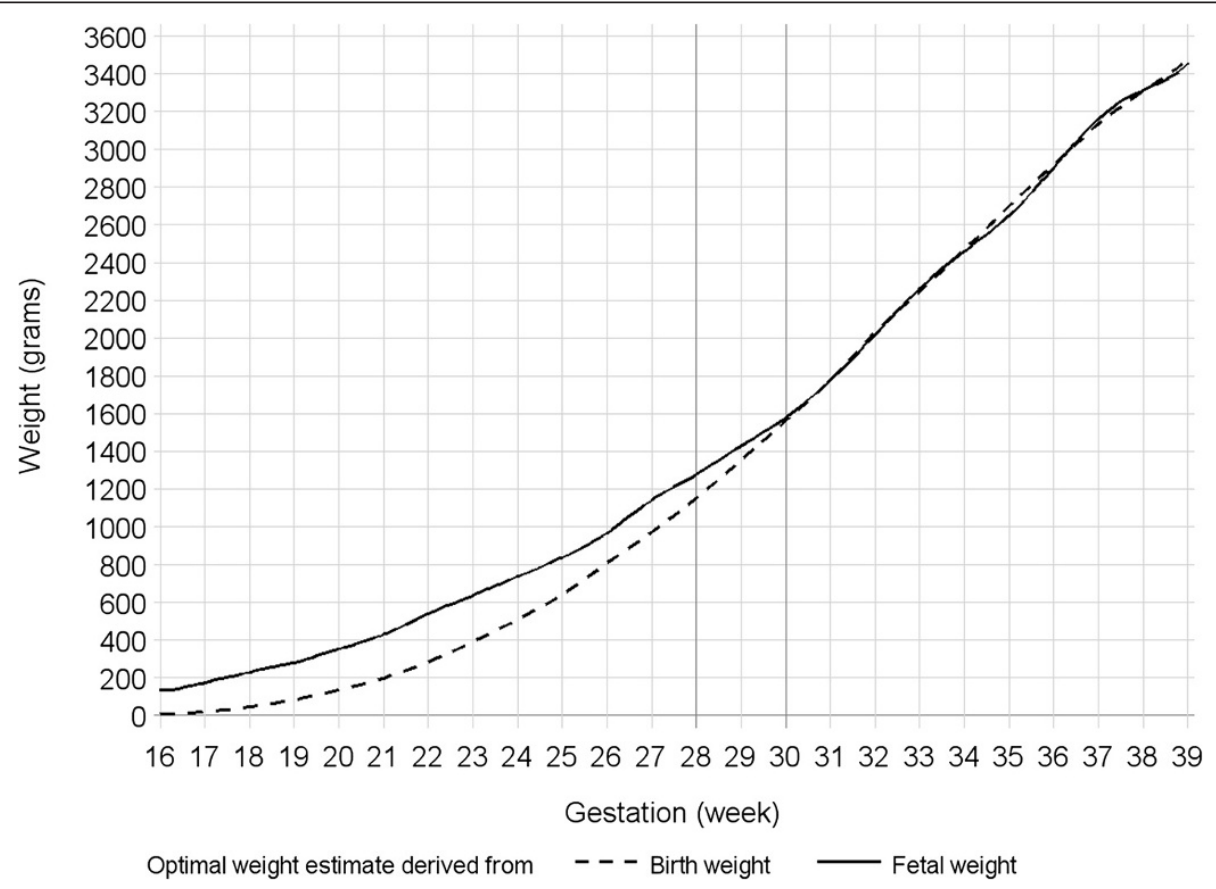

Figure 2 Curves for the mean $\mathrm{OW}_{\mathrm{BW}}$ and $\mathrm{OW}_{\mathrm{US}}$ by gestational age. 


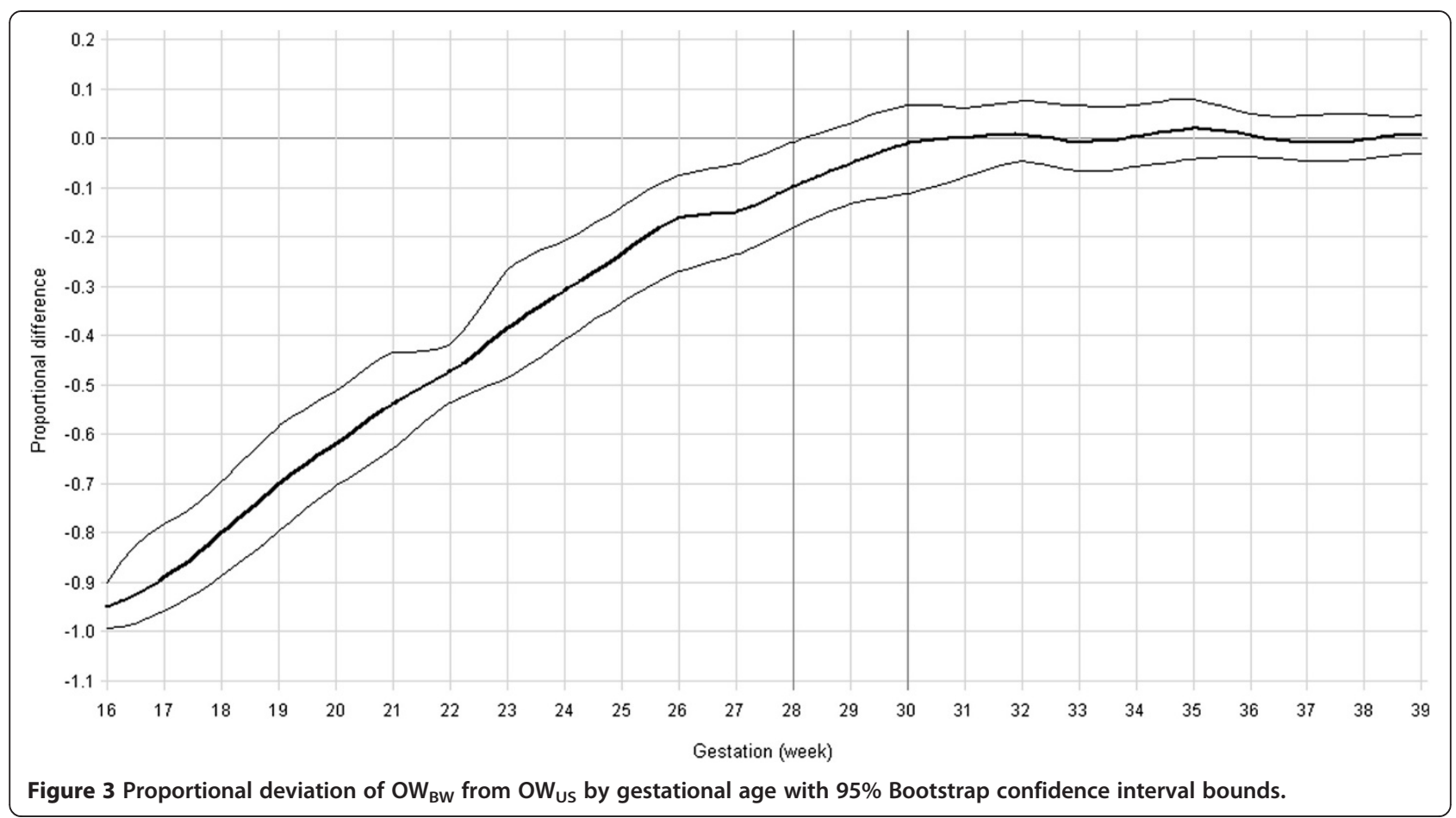

median of the birth weight distribution between 25 and 35 weeks of gestation [6]. However, their inclusion of individuals subsequently born pre-term, those exposed to maternal smoking during pregnancy, and those with known growth restricting pathologies would have deflated the true discrepancy. Not accounting for known non-pathological determinants of growth such as birth order and maternal stature would have introduced further error. Moreover, the proportional difference between the two approaches may be of greater interest than the absolute difference as it is a measure of difference relative to the fetal size. Our results indicate that the proportional deviation of $\mathrm{OW}_{\mathrm{BW}}$ from $\mathrm{OW}_{\text {US }}$ was statistically significant prior to 28 weeks gestation, after accounting for individualised growth potential and excluding those with diagnosed growth restriction or known growth restricting pathologies. From 30 weeks of completed gestation the estimates of fetal weight based on a population of birth weights not exposed to common causes of growth anomaly yielded similar estimates of optimal weight.

The methodology that we applied differs from those suggested by others in that centiles and z-scores were not produced [14]. However, the aim of our study was to compute and compare the mean optimal fetal weight derived from both ultrasounds and neonatal measurements to that derived from only birth weights, rather than produce reference charts and compare the entire distributions. Nonetheless, we responded to the recommendations of Altman et al (1994) as we fully accounted for the non-constant variance of the residuals with increasing gestational age [15]. Albeit small in magnitude, the temporal autocorrelation among the fetal weights was statistically significant after accounting for gestational age, birth order, infant sex and maternal height. Therefore, past studies that ignored the temporal autocorrelation violated this requirement for regression. A limitation of our approach is the increased complexity of modelling the error variance. A further limitation of our study was that the exclusion criteria restricted the sample size from 9,222 scans to 2,848 scans. However, this meant that the expected optimal fetal weight estimates were less likely to be influenced by individuals with pathologically affected growth. The prospective design also allowed the retention of multiple scans per individual despite these exclusions.

\section{Conclusion}

It remains to be demonstrated that preterm births can be considered optimally grown if they are not exposed to common factors that perturb fetal growth. The model derived from both fetal and neonatal weights in this study is recommended before 30 weeks of gestation. From 30 weeks gestation the two models were indistinguishable.

\section{Competing interests}

The authors declare that they have no competing interests.

\section{Authors' contributions}

GP participated in the design of the study, performed the statistical analysis, and wrote the initial manuscript and later revisions. EB conceived the study, participated in its design and helped to draft and revise the manuscript. $\mathrm{DL}$ 
Received: 6 April 2011 Accepted: 4 June 2012

Published: 15 June 2012

\section{References}

1. Roberts CL, Lancaster PAL: Australian national birthweight percentiles by gestational age. Medical Journal of Australia 1999, 170:114-118.

2. Kramer MS, Platt RW, Wen SW, Joseph KS, Allen A, Abrahamowicz M,

Blondel B, Breart G, for the Fetal/Infant Health Study Group of the Canadian Perinatal Surveillance S: A New and Improved Population-Based Canadian Reference for Birth Weight for Gestational Age. Pediatrics 2001, 108:e35.

3. Doubilet PM, Benson CB, Wilkins-Haug L, Ringer S: Fetuses Subsequently Born Premature Are Smaller Than Gestational Age-Matched Fetuses Not Born Premature. J Ultrasound Med 2003, 22:359-363.

4. Cooke RW: Conventional birth weight standards obscure fetal growth restriction in preterm infants. Archives of Disease in Childhood Fetal \& Neonatal Edition 2007, 92:F189-F192.

5. Ehrenkranz RA: Estimated fetal weights versus birth weights: should the reference intrauterine growth curves based on birth weights be retired? Archives of disease in childhood Fetal and neonatal edition 2007, 92:F161.

6. Salomon LJ, Bernard JP, Ville Y: Estimation of fetal weight: reference range at 20-36 weeks' gestation and comparison with actual birth-weight reference range. Ultrasound in Obstetrics and Gynecology 2007, 29:550-555.

7. Blair EM, Liu Y, de Klerk NH, Lawrence DM: Optimal fetal growth for the Caucasian singleton and assessment of appropriateness of fetal growth: an analysis of a total population perinatal database. BMC Pediatrics 2005, $5: 13$.

8. Hadlock FP, Harrist RB, Fearneyhough TC, Deter RL, Park SK, Rossavik IK: Estimation of fetal weight with the use of head, body, and femur measurements. A prospective study. American journal of obstetrics and gynecology 1985, 151:333.

9. Anderson NG, Jolley IJ, Wells JE: Sonographic estimation of fetal weight: comparison of bias, precision and consistency using 12 different formulae. Ultrasound in Obstetrics and Gynecology 2007, 30:173-179.

10. Scott F, Beeby P, Abbott J, Edelman D, Boogert A: New formula for estimating fetal weight below $1000 \mathrm{~g}$ : comparison with existing formulas. J Ultrasound Med 1996, 15:669-672.

11. Box GEP, Cox DR: An analysis of transformations. Journal of the Royal Statistical Society. Series A: Statistics in society; 1964.

12. SAS Institute Inc: SAS 9.1.3 service pack 4. NC, USA: Cary; 2003.

13. Efron B, Tibshirani RJ: An introduction to the bootstrap. New York: Chapman \& Hall; 1993

14. Silverwood RJ, Cole TJ: Statistical methods for constructing gestational age-related reference intervals and centile charts for fetal size. Ultrasound in Obstetrics and Gynecology 2007, 29:6-13.

15. Altman DG, Chitty LS: Charts of fetal size: 1. Methodology. BJOG: An International Journal of Obstetrics \& Gynaecology 1994, 101:29-34.

doi:10.1186/1471-2431-12-73

Cite this article as: Pereira et al:: Validation of a model for optimal birth weight: a prospective study using serial ultrasounds. BMC Pediatrics 2012 $12: 73$.

\section{Submit your next manuscript to BioMed Central and take full advantage of:}

- Convenient online submission

- Thorough peer review

- No space constraints or color figure charges

- Immediate publication on acceptance

- Inclusion in PubMed, CAS, Scopus and Google Scholar

- Research which is freely available for redistribution

Submit your manuscript at www.biomedcentral.com/submit 